\title{
DIGITAL TRANSFORMATION AND RELATIONSHIP WITH CUSTOMER EXPERIENCE: A CRITICAL REVIEW OF LITERATURE FROM 1990 TO 2005 FOR PARADIGM SHIFTS IN KNOWLEDGE AND THOUGHTS IN 4-WHEELER CAR SEGMENT
}

\author{
Prakash Wagh \\ Research Scholar, MIT Art, Design and Technology University, Pune, Maharashtra, India
}

\section{Dr.Ajim Shaikh}

Assistant Professor \& Guide, MIT Art, Design and Technology University, Pune,

Maharashtra, India

\begin{abstract}
Digital transformation and its relationship \& impact of front end (Customer), especially on customer experience and customer satisfaction has been a focus of study for last three decades. What has started purely as a "After sales service" initially changed to service dominant logic, Customer relationship management and customer experience with evolution in thoughts accompanied by deep leaps in digital technology from computers of 1 ob960's to totally digital world of today. The changes in digital technology helped the "Front end-Customer side" to be in sink with the demands of the customers and paradigm shift in the customer service thoughts, knowledge and practice. This review of literature is based on relationship between digital transformation and customer experience from 1990 to 2005 period, which saw a dramatic change in both these areas. Going hand in glove with each other digital transformation and customer experience has contributed to paradigm shift both internally \& externally for business and end customers
\end{abstract}

Key words: Digital transformation, Customer Satisfaction, Service dominant logic, customer experience

Cite this Article: Prakash Wagh and Ajim Shaikh, Digital Transformation and Relationship with Customer Experience: A Critical Review of Literature from 1990 to 2005 for Paradigm Shifts in Knowledge and thoughts in 4-Wheeler Car Segment, International Journal of Management, 11(12), 2020, pp 2098-2110.

http://iaeme.com/Home/issue/IJM?Volume=11\&Issue $=12$ 


\section{INTRODUCTION}

Digital transformation refers to the ways in which the companies or business change their business strategy and models to adapt to a new technology and customer preferences, this is an umbrella term for many changes and involves multiple technologies. While customer experience is the product of an interaction between an organization and a customer over the duration of their relationship. While digital transformation virtually impacts all aspects of internal and external environment, it's most significant impact as per the current research is on "Customer experience". The front-end phenomenon seems to overcast the other value benefits of digital transformation.

It is deduced from the existing multiple research and studies that there is a significant relationship and impact associated between the digital transformation initiatives and the customer experience. However, most of these research and studies concentrated on digital products like banking, hospitality, booking sites and telecom and few studies attempted to go for high value physical products study or what we call as primary industries like Automobile, which this study is trying to investigate,

While digital products study does collaborate that those digital product companies or organizations which are likely to strike a chord in customer experience are likely have to greater customer loyalty, return purchases, high level of customers satisfaction and high level of word of mouth publicity among peers. Currently the digital transformation and customer experience for high value physical product especially in 4-wheeler segment is still not that got that much focus or gets attention. This is inspite of large-scale adoption of digital transformation by Automobile companies in last one and half decade and turning themselves customer centric.

The Current research points out the benefits of digital transformation which includes internal business benefits such as increased productivity, streamlined business processes ,real time supply chain and adoption of automation of shop floor as well as external benefits to sales and marketing including the good customer connect, multi-channel access for customer ,continence and ease for customers, customer satisfaction and customer experience. The focus of my research is on "Customer experience". The attempt is to deep dive and assess the impact of digital transformation on various aspects of customer experience which is a journey which starts from awareness - acquisition-post purchase experience- lifetime loyalty.

This paper has attempted deep dive in digital transformation and relationship with customer experience for the period 1990 to 2005 with the available academic and business literature related primarily to automobiles and in particular 4-wheeler (car) segment.

\section{OBJECTIVES OF THE STUDY}

This study on review of literature on relationship between digital transformation and customer experience from the period 1990 to 2005 have following objectives :

- To find out the various research works that have been done in the area digital transformation and its relationship with customer experience during the period of 1990 to 2005 for 4 wheeler car segment.

- To highlight the various factors which affect customer experience including the main factor of digital technologies that help to enhance front end experience for car owners.

- To highlight the knowledge and model changes in customer experience due to rapid changes in digital transformations/Technologies during this period for 4-wheeler car segment. 


\section{METHODOLOGY}

This study of literature is mainly based on secondary sources of data like thesis, journals, business articles, Books ,business blogs, surveys and thought leadership articles from 1990 to 2005. It is in descriptive nature . The search for the relevant literature is done through both online and offline mode , online mode being prominent. The search criterion used in locating the right sources is used based on the key words of "Digital transformation and Customer experience" with large number of variations in basic search criterion to get the right literature for this study.

The secondary sources scanned includes more than 20 doctoral thesis, more than 100 research articles, more than 70 blogs ,survey and business articles. The most important sources are filtered through based on relevance to the topic, contribution to the base knowledge and models and relationship with the primary industries like automobile. The literature related to non-automobile ( 4 -wheeler cars) is mostly omitted to make the study centered around the car segment, though some interesting non-automobile papers are included due to some new insights and thoughts provided into it.

\section{RELATIONSHIP BETWEEN DIGITAL \& CUSTOMER EXPERIENCE FOR 4 WHEELERS (CARS) BASED ON REVIEW OF LITERATURE}

This section elaborates various author and their findings on digital transformation and customer experience in the same period starting from 1994 till 2000.We have called this period as " formative period" wherein most of the current knowledge ,models between digital and customer experience took the shape, initially for service industry ,rapidly followed by primary physical industries like Automobile. While period from 2000 to 2005 have been labeled by us as " Growth period "wherein lot of transformation activities happen in customer experience area due to rapid changes in digital transformation or digital technologies.

Digital transformation and customer experience literature review is presented below in the chronological order helping us to understand the changes in concepts, Frameworks, Methodologies and technologies over the time including gaps to be bridged and future scope for work in these areas. The research article has taken a broad review of literature from 1994 to 2005. (Formative years till 2000 and growth period 2000-3005)

\subsection{Formative Period (1990-2000)}

Holbrook and Hirschman (1982) in their article "Experiential aspects of consumption : Consumer fantasies ; feelings and fun" argue that the information perspective on customer experience can be challenged on the ground that it is neglecting consumption phenomenon which include playful leisure activities, sensory pleasures daydreams, aesthetic enjoyment and emotional responses. They further argue that this "experimental view "is very important and needs to be further studied and investigated

The authors further explain that current customer research is too much obsessed with benefits on conventual goods and services what they call as utility value of product or service. However, they claim that in this utility view, symbolic meanings of more subjective characteristics like cheerfulness sociability and elegance is ignored

The authors point out to the fact that most of the human activities are relatively pleasure oriented consumption and attention must be given to hedonic components. They raise issue of developing measures for hedonic responses, reliability and validity as hedonic expressions very among seekers as well as using such indices. The authors also argue that personality 
traits based on demography, socioeconomic status and psychographics fairs poorly in predicting consumer behaviour and there is a need to shift to lifestyle variables.

The Authors conclude that from the information processing perspective, consumer choice is seen typically as a utility or usefulness function. In contrast the experimental view, consumption in the fun that drives the consumer towards a product or service. (i.e. customer experience). We can see "Customer experience" seeds started germinating from 1982.

Carbone and Haeckel (1994) in their research article "Engineering customer Design" explains that the firms or product team gets experience clues either performance based, or context based. They argue if these clues are systematically crafted into net positive impressions, it promotes customer preferences which a company can leverage to differentiate it from the competitors.

The authors further argue that in engineering, experience management is mainly concerned with systematic planning and design of context clues that are emitted by product or service and the environment around.

In terms of taking a more strategic and holistic approach to experience design they have divided experience design into four phases; 1) acquisition of service experience design skills, 2) data collection and analysis, 3) service clue design, and 4) implementation and verification.

The authors further explain that the blueprint with many constituencies as possible and set of clues is chosen from alternate options and validated for cost, specification and impact. It is communicated across the organization for promoting awareness and getting the buy in from internal stakeholders. The authors have called managing the clue as a "New Frontier". This study has further strengthened "Holbrook and Hirschman (1982)" earlier argument.

Alexa Kierzkowski; Shayne McQuade; Robert Waitman \& Michael Zeisser (1996) in their research article "Marketing to the Digital Consumer"claim that most of the firms are using the interactive media in static, one way, mass marketed broadcast model of traditional media. They further state that such an approach is failing to tap the full potential of internet and world wide web. Their study is aimed at finding and reviewing the current status of marketing to digital customers and ways to improve the current usage models.

The author believes that the digital marketing model is a very attractive tools for more and more consumer products and services than it is assumed today. They feel it should be tried in financial services, books, food, beverages and explore how to capture the opportunities in the digital world.

The authors suggested a framework for the planned digital marketing journey with five phases namely- ad hoc stage; Focus stage; Formalizing phase and institutionalizing phase and under each phase changes are required into organization, structure, people, skill and funding source.

Authors claim that in next three to five years interactive marketing is likely to become an increasingly significant part of marketing landscape. They also suggest that digital marketers could get excellent yield if they work on three important factors -Company, competition and the category. The importance of digitization was identified way back in 1995 .

Raymond Burke (1997) in his article "Do you see what I see ? the future of virtual shopping " who has built his article on the original contribution of Peterson et tal (1997), where their analysis, that impact of the internet on consumer marketing is overstated as it fails to understand the complexity and heterogeneity of the market.

Author has tried to explore the reasons why it is so difficult to predict or forecast the effect of the new communication technologies on verticals like retails. He also tries to discuss the ways by which the retailers should respond to the new communication technologies; how the internet and electronic shopping will continue to evolve and finally suggest how the retail 
management plan. So, there were conflicting opinions then about the impact of IT technology on customers amongst the researcher even during 1997 when internet technology has taken firm roots.

Author says Manufacturers, retailers and consumers have their own motivations and constraints with electronic shopping, but their plans and actions are independent. Author says the success of internet-based shopping programs will depend upon how well, they are planned. Promoted and executed and the quantity and quality of the competitive response. He has suggested two approaches for firms and managers, let the technology mature ,be ready by that time and then take a plunge or start now, take an active role, define and initiate the digital programs.

Christensen (1997) in his book "The Innovator's Dilemma: When New Technologies Cause Great Firms to Fail". Argues that unless the successful campiness and its leaders are in tune with time and adopt the new innovations in business, they fail. The book gives framework and rules for companies to capitalize on the phenomenon of disruptive innovation.

The Author certain common principles to be followed by the existing firm which is a must for survival and progress and includes: Resource dependence, small market struggle impact, Fluid disruptive technologies, core processes and capabilities \& proper use of technology in the right market.

The Author suggests following strategies assist, existing firm must protect against the disruptive technologies: The firm develops disruptive technology with identified, right customers. The firm then gives this technology into an autonomous organization which can be rewarded with small wins and small customers. If there is earlier failure, then firm need to correct disruptive technologies. They allow their autonomous companies to use all the main companies' resources when needed.

My research topic digital transformation and customer experience tries to establish the relationship between digital innovation and its notional impact on customer experience. This book gives much needed insights needed for this intended research.

Anitesh Barua, Sury Ravindran \& Andrew B. Whinston (1997) in their research article "Efficient Selection of Suppliers over the Internet" aim at an idea that organizational buyers use the internet as a source of information for supplier evaluation and selection. They argue that vast amount of product and vendor data is available on the network, what should be the best strategy to adopt and exploit the technology and identify good suppliers with less efforts. Besides there is question can internet application and engines suggest focused and suitable initial pool of suppliers.

The in-depth study acknowledges that electronic networks do have brought new opportunities as well as challenges in business operations by reducing the cost of search and communication. They argue that internet can help organization in time and optimization cost for only standard products, appropriate strategies are needed if buyer must evaluate both standard and nonstandard, efficient and non-efficient suppliers. They also study sequential evaluation and bidding systems and assessed their suitability for selecting suppliers based on various technical and commercial capability factor.

They have suggested that intelligence search engines can really help buyers in selecting the right supplier in optimum time and cost.

Pine and Gilmore (1998) in their research paper "Welcome to the Experience Economy", state that an experience "occurs "when a company intentionally uses services as the stage, and goods as props, to engage individual customers in a way that creates a memorable event". This view fixes the experience firmly in the practitioners' domain but also includes the customer in it, 
The authors further elaborate that the likely characteristics of the experience economy and the kinds of changes it will force companies to make. First there was agriculture, then manufactured goods, and eventually services. Each change represented a step up in economic value--a way for producers to distinguish their products from increasingly undifferentiated competitive offerings. Now, as services are in their turn becoming commoditized, companies are looking for the next higher value in an economic offering. Leading-edge companies are finding that it lies in staging experiences.

And while experiences have always been at the heart of the entertainment business, any company stages an experience when it engages customers in a personal, memorable way. The lessons of pioneering experience providers, including the Walt Disney Company, can help companies learn how to compete in the experience economy. The authors offer five design principles that drive the creation of memorable experiences. First, create a consistent theme, one that resonates throughout the entire experience. Second, layer the theme with positive cues--for example, easy-to-follow signs. Third, eliminate negative cues, those visual or aural messages that distract or contradict the theme. Fourth, offer memorabilia that commemorate the experience for the user. Finally, engage all five senses--through sights, sounds, and so on-to heighten the experience and make it more memorable.

Cassill, Nancy L. (1998) in her article "Do customer returns enhance product and shopping experience satisfaction?" whose objective of the study was to compare product and shopping experience of two groups, one who has purchased the product recently and returned and other group who had purchased the product almost a year earlier and then retuned.

The study found that the two consumer groups differed in reasons for returning the product, frequency of dissatisfaction with purchase of that product and degree of dissatisfaction with the shopping experience. The two customer groups did not differ in dissatisfaction with the stores return process. Latent customers were more frequently dissatisfied with the product and shopping experience than the recent return customers. Recent return group showed enhanced product and customer satisfaction. Customer return process is an equally important part of overall customer satisfaction and customer experience. Firms And managers need to have a streamlined an organization wide process management.

George, J. M. (1998). In his article "Salesperson mood at work: Implications for helping customers." Makes a strong emphasis that front end executives and their approach to customers play a very vital role in understanding individual customer needs and aspirations. The Salespersons or front-end executives with their positive mind sent, excellent service, behavior protocols may impress the customer. The sales lead at the front end is expected to create this positive mindset and customer friendly environment at the front end.

Author stresses the importance of salesperson helping behavior directed at customers and his total focus is on understanding the customer, his expectations, needs and desires. In doing so he must be cheerful, cooperative, collaborative and friendly with customer. The author says the salespersons mood at work is determinant of how helpful they are to the customer and quality of service provided to customer. He further suggests that positive mood at the work can be enhanced by promoting a sense of competence. achievement. good workplace, motivational schemes like rewards and recognition and keeping the team size small.

Seth J.N. et tal (1999) in their book "Customer Behavior: Consumer Behavior and Beyond" propounds the idea that customers attitude to an event is a combination of three factors: 1. Stimulus characteristics Customers perceive a stimulus differently according to information received or sensory experience they receive. Stimuli that differ from other stimuli are more likely to be noticed 2 Context: When perceiving a given set of characteristics individuals are also affected by the context of stimuli 3 Situational variables: This is 
inclusive of information received through social, cultural and experience with product or service. These shape perception.

Dave Chaffey \& Fiona Ellis-Chadwickian (2000) their book published by Pearson titled "Digital Marketing" elaborates on various aspects of digital marketing from definition, strategy, execution, technology, customer experience, performance measurement of channels with examples and relevant references.

The Authors state that digital marketing faces many problems like unclear responsibilities with many different marketing activities, no specific measures or targets set, insufficient budget allocation, budget waste in experimentation, Value preposition to online customers not clearly defined and developed and action or experimental approach instead of planned strategy and implementation for digital marketing,

Authors feel that systematic digital transformation projects are necessary to reap the real value of digitization and avoid the piece meal approach mentioned above. Authors feel that 7 $\mathrm{S}$ framework can be applied to understand current and future capabilities in digital which will help to draw the digital transformation strategy. These seven factors include: Strategy, structure, system, staff, style, skills and superordinate goals.

Authors has also suggested use of RACE model to identify how the digital channels can help to meet the business objectives and consists of : Reach, Interact, Convert and Engage steps which can help organization to understand how digital can help them engage the prospects, customers and fans with brands throughout the customer lifecycle.

Authors have also commented on versality of digital medium in marketing communication due to the inherent characteristics of: Interactivity, intelligence, individualization, I“;" Joy restructuring, integration \& independence of location which mark them more versatile than traditional communication channels.

Authors has stressed that a deep study and understanding the individual nature of customers is a foundation of digital marketing practice. And planning. Variables like demographic variables, Psychographic and behavioral variables are important in understanding customer behavior. Author further states that consumer background of online concept decide the positive or negative response to digital offers and consists of concepts like information processing, perceived ease of use, perceived usefulness, perceived benefits, perceived controls 'skill, trust\& risk and enjoyment.

Author has mentioned that in the digital marketing due to omni channels it has really become difficult to integrate all the channels for collecting and analyzing customer interactions and clues. They have cited websites, social media, social groups, networking sites, Facebook, twitter and so on. The author argues that digital presence must be "effective" means it must create desired customer experience for the customer at the same time it must support and add value to the brand to deliver results for the company. The Authors have defined "conversion ratio optimization" which is defined by them as "Improving the commercial returns from a transactional site through increasing conversion to key goals such as sales, quotes, bookings or leads. CRO combines customer and competitor research with evaluation of customer behavior using web analytics and $\mathrm{AB}$ and multivariate testing “

Based on the existing study's authors have suggested that delivering the online experience promised by a brand requires delivering rational values, emotional values and promised experience (based on rational and emotional values). The factors that influence the online customer are: Product, interactivity; service, Design, Reassurance, ease of use, relevance and performance. This book has further augmented the relationship between digital transformation and customer experience. 
The period from 1992 to 2000 , was found to be a formative period both for customer experience and digital transformation (Mostly internet for marketing). The research during 1992 to 2000 added certain important "Paradigm shifting "ideas and thoughts such as:

- Customer clues: which needs to be incorporated into product design \& Service.

- Static way of use of internet \& world wide web: limiting ability to tap full potential of the internet and world wide web.

- Understanding complexity \& Heterogeneity of market: It was pointed that, then the internet and world wide web was failing to address the customization, personalization and experience.

- Experience economy: Use product or services, to engage individual customers in a way that creates a memorable even.

- Customer behavior: customers attitude to an event is a combination of three factors namely stimuli, context $\&$ situation variables.

- Digital marketing: 1992 to 2000 saw, emergence of digital marketing as a separate discipline within marketing starting from internet marketing in 1994-1995.

\subsection{Growth Period}

The period from 2000to 2005 was a period of intense academic and business adoption of ideas in both the areas of digital transformation (from only digital marketing in earlier decade) to full-fledged "Customer experience" ( From SDM logic and CRM, Thought process started moving to a broader umbrella of customer experience.)

Wind \& Mahajan (2002) observed that the internet and the digital channels have made available enormous quantity of information to customers about product and services, reviews and feedback .while James Lawson (2002) shared their experience of going digital in reducing the customer churn in the TV channel broadcasting business Leonard L Berry, Lewis P. Carbone and Stephan H. Haeckel (2002) pointed that firms and managers have becomes more aware of the need and necessity of creating value for their customers in the form of experiences

Kim (2002) suggested that based on the consumer experience and value offered by each mall and internet shopping site, retailers should implement strategies that will lead to enhanced customer experience. While Lauren Keller Johnson (2002)" tried to weigh the pros and cons induced by use of internet in customer relationship management (CRM

Gillian Sullivan Mort \& Judy Drennan (2002) has given 2 frameworks which help firms or marketing managers to identify how movement to mobile marketing impacts the customer behavior and shape the corresponding marketing strategies' while Shaun Smith and Joe Wheeler (2002) have covered detailed about the brands, their loyal advocates, people, leadership and customer experience phenomenon in their book.

Dave Chaffey (2002) in his book" has suggested to address the digital and ecommerce management in a structured way starting from strategy, implementation, monitoring and continuous improvements. While Reid Goldsborough (2002)" admits using an analogy that "don't ask me which seed will grow and which will not". She was skeptical whether digital technology will survive or not, but the apprehension proved wrong,

Sandy D. Jap \& Jakki J. Mohr (2002) have tried to review the pitfall of the initial internet ventures and advise on how internet technologies can be successfully used in B2B scenarios. While C.K. Prahalad \& Venkatram Ramaswamy (2003) explained that the emerging competitive landscape catalyzed by the digitalization has changed the boundaries or atleats made them blur. 
Angela Andal-Ancion et tal(2003 ) worked on seeing key drivers which organizations must use if they really want to make resourceful and productive use of new age technology and listed management \& technological parameters while. Mimi Sheller (2003) challenged that car consumption is not alone a rational decision related to economic choice but it is as much about the aesthetic ,emotional and sensory responses to divining ,kinship ,sociability ,habitation and work. The traditional rational economic approach is challenged in this article.

Negi and Saklani (2003), proved that wide variety, personalization and customizations were the prime motivators for customers to opt for online buying, While Schmitt (2003). came out with a five-step framework for implementing customer experience framework. (CEM)

Wong, A., \& Sohal, A., (2003) concluded that service quality is positively associated with customer loyalty, and that the relationship between the two is stronger at the company level, rather than at the interpersonal level. While Harris, R., Harris, K. and Baron, S. (2003) provided a framework for the development of a dramatic script for a service (retail) organization. They argued that such a script can lead to an agreed experiential goal that the organization can use to achieve positive holistic service experiences for customers.

Stephan H, Haeckel et tal (2003) in their article made a point that customers overall experience is influenced by sensory and emotional clues .while Gordon A. Wytter (2003) in his research argued that the current research methods have not kept pace regarding need for information about customer experience \& measurement and suggested an approach for measuring the CX.

Day, G. S., \& Hubbard, K. J. (2003) found that through there is largely positive opinion about internet being a versatile medium but companies are also worried about price war and competition. While Erik Stolterman \& Anna Croon Fors (2004) in their article, has elaborated that information technology has become part and parcel of our daily lives. They call this it is radical digital transformations in our daily lives.

Eugene F. Demark \& Robert R. Harcourt (2004) in their article claim that internetbased model and digital technology adoption is the way forward. While Poulsson and Kale (2004) in their article observe that until 2004 there were no systematic attempts to define exactly what constitutes an experience in marketing terms. They have presented an operational definition of what constitutes a commercial experience.

Lewis P. Carbone (2004) in his book says very few companies manage their customer and customer experience well and turn these customers into lifelong loyal customers. While Alison Bond \& Merlin Stone (2004) in their research article concluded that customers know, what they are paying but not what they are buying.

Alexandra Thusy and Langdon Morris (2004) in their research tries to probe the ways and means to provide the consumers with great and compelling customer experiences which can create enduring memories and ever lasting relationships. While Yi-Ching Hsieh; HungChang Chiu \& Mei-Yi Chiang (2005) in their research article found that financial, social and structural bonds have positive impact on the customer commitment.

Shaw, Colin (2005), in his book, have classified companies in four stages as Naïve, Transactional, Enlightened, and Natural which helps organization to revolutionize themselves into offering them great customer experience from stagewise journey. While Sunil Mithas M. S. Krishnan Stephen Claes Fornell (2005) in their research article found that the effect of IT investments on customer satisfaction is mediated through the effect of IT on perceived quality and perceived value, thus proving that IT initiave do contribute to the customer satisfaction.

Sunil Mithas et tal (2005) in their research article found that CRM applications are positively associated with an improvement in customer knowledge. Also, there is a close 
association between CRM and customer satisfaction which is mediated by the effect of CRM applications on customer knowledge. while Bain \& Company (2005) pointed out that 3 D's namely Design, Develop and Deliver together ensure that the company or business is guided by "Voice of Customers"

We have labelled this period from 2000 TO 2005 as a growth period both for customer experience and digital transformation. While the strong correlation between the digital transformation and customer experience is proved beyond doubt, during this period, the major contribution to body of knowledge and "Paradigm shifts" in these, Some of the main areas are briefly summarized below.

- Digital transformation journey supported by deep studies from strategy to implementations, models and key success factors have been added by various contributors.

- Digital technology as an enabler for customer experience management, contributor to top and bottom line has been established.

- The application of digital technologies has reached beyond the traditional industries and reached to primary physical industries as Automobile, which has adopted itself to this change.

- Various new technologies such as big data, analytics, Blockchain and IOT has been added to the digital transformation bucket list,

- Customers expectation of digital interfaces, social media and real time communications have reached its highest point and as such companies were also engaged in responding to this demand.

- In customer experience area, the traditional SDL and CRM came under the overall umbrella of CX.

- Customer experience, brand and word of mouth research has dominated the decade,

- Rational economy theory for customer experience (Utility) was further enhanced by proven research in hedonic factors and transcend experience.

- Interdisciplinary studies on customer experience including psychological factors, experience factors and transcended factors added more insights into customer experience phenomenon.

- Many new models and methodology for "CX" implementations in an organization with elements and key success factors are added during this decade.

- Some studies of measuring the "Customer experience" added to the existing ways of measuring the customer experience.

\section{CONCLUSION}

- Both digital transformation and customer experience has undergone "Paradigm shift" in knowledge base, technology, thought process over the period of 1990 to 2005.

- The period of 1990 to 2005 can be divided into two main themes

o Formative period (1994.2000)

o Growth period (2000- 2005)

- What started as internet marketing and which was initially seen with suspicion, after 2000 has really transformed the way customer facing processes works.

- SDL (Service dominant logic) to CRM (Customer relationship management) has got transformed further with a broader concept of Customer experience. 
- The penetration of the mobiles and gadgets, strong social media platforms have resulted into empowered and knowledgeable customer.

- Most of the companies have adopted the journey of digital transformation as well more focus on creating rich customer experience.

- While various authors have provided multiple models for implementation of digital initiatives as well as customer experience, one common thread among all these authors is that digital transformation have a strong contribution and positive effect on enriched customer experience.

\section{REFERENCES}

[1] Holbrook and Hirschman (1982). The Experiential aspects of consumption: Consumer fantasies, feelings and fun. The journal of consumer research, Volume 9, No. 2 (sept 1982). Pages 132-140.

[2] Carbone and Haeckel (1994). Engineering customer Design .Marketing Management; Chicago Vol. 3, issue. 3, (Winter 1994).

[3] Alexa Kierzkowski; Shayne McQuade; Robert Waitman \& Michael Zeisser (1996). Marketing to The Digital Consumer. The McKinsey Quarterly; New York Issue. 3, (1996): 4.

[4] Raymond Burke (1997). Do you see what I see ? the future of virtual shopping. Journal of the Academy of Marketing science., Volume 25, no. 4 ;Pages 352-360.

[5] Christensen (1997). The Innovator's Dilemma: When New Technologies Cause Great Firms to Fai. Harvard Business school press. Boston. edition1. 1997. ISBN 0-87584- 585-1) 32750.

[6] Anitesh Barua, Sury Ravindran \& Andrew B. Whinston (1997). Efficient Selection of Suppliers over the Internet. Journal of Management information system. Volume 13,issue 4, 1997.Pages 117-137.

[7] Pine and Gilmore (1998). Welcome to the Experience Economy”, Harvard Business Review. July-August 1998.Pages 97-105.

[8] Cassill, Nancy L. (1998). Do customer returns enhance product and shopping experience satisfaction? The international Review of Retail, Distribution and consumer Research. Volume 8, 1988.issue 1.Pages 1-13.

[9] George, J. M. (1998). Salesperson mood at work: Implications for helping customers. Journal of Personal Selling \& Sales Management. Volume 18, 1998-Issue 3.Pages 23-30.

[10] Sheth. J. N. Mittal, B. and Newman, B.I. (1999). Customer Behavior: Consumer Behavior and Beyond, The Dryden Press Harcourt Brace College Publishers, New York, NY.

[11] Dave Chaffey \& Fiona Ellis-Chadwickian (2000) .Digital Marketing. Pearson Publishing. Edition 1. ISBN 978-0273746102.Pages 728.

[12] Wind \& Mahajan (2002). Convergence Marketing. Journal of interactive Marketing. 16(2).Pages 64 -79. DOI: 10.1002/dir.10009. https://doi.org/10.1002/dir.10009

[13] Lawson James (2002) .Do not touch that dial. Retrieved from www.direct.magazine.com. Pages 30-31.Primedia business magazines \& Inc.

[14] Berry Leonard L, Carbone Lewis \& Haeckel Stephan (2002). Managing the Total Customer Experience. MIT Sloan Management Review. Spring 2002. Volume 43, Number 3.Pages1-6.

[15] Kim, Y. (2002).Consumer value: an application to mall and Internet shopping. International Journal of Retail \& Distribution Management, Vol. 30 No. 12, pp. 595-602. https://doi.org/10.1108/09590550210453075. 
Digital Transformation and Relationship with Customer Experience: A Critical Review of Literature from 1990 to 2005 for Paradigm Shifts in Knowledge and thoughts in 4-Wheeler Car Segment

[16] Johnson, Lauren Keller. New views on digital CRM: managers' opinions vary about the goals and value of Internet marketing. (E-Business). MIT Sloan Management Review, vol. 44, no. 1, 2002, p. 10.

[17] Mort, G., Drennan, J. Mobile digital technology: Emerging issue for marketing. J Database Mark Customer Strategy Management.10, 9-23 (2002).

https://doi.org/10.1057/palgrave.jdm.3240090

[18] Smith Shaun Smith \& Wheeler Joe (2002). Managing the customer experience-Turning customer into advocates. Pearson publisher. Edition1.Sept 2002.Pages 254.

[19] Chaffey Dave (2002).Digital Business and E-Commerce Management: Strategy, Implementation \& Practice. Financial Times/Prentice Hall Publishers.2 edition. 2011. ISBN 978-0273752011.

[20] Goldsborough Reid (2002). Prophesying the future of Digital technology. Tech Directions. Feb.2002.Volume 61, issue 7, P 11.3/4p.

[21] Jap Sandy \& Mohr Jakki (2002).Leveraging internet Technologies in B2B Realtionships. California Management Review. Volume 44, issue 4, 2002, Page(s) 24-38. https://doi.org/10.2307/41166141

[22] Prahalad C.K \& Ramaswamy Venkatraman (2003).The New Frontier of Experience management. MIT Sloan Management Review. Summer 2003.Vol.44, No.4, PP12-18.

[23] Cartwright, Phillip \& Andal-Ancion, Angela \& Yip, George. (2003). Digital Transformation of Traditional Businesses. MIT Sloan Management Review. 44. 34-41.

[24] Sheller Mimi (2003).Automotive emotions: Feeling the car. Journal of theory, culture and society. Volume 21, Issue 4-5, 2004 .sage, PP 221-242.

[25] Negi and Saklani (2003). Understanding Behaviour of Online Shoppers. Delhi Business review. Volume 4, issue 2, 2003.PP 103-107.

[26] Schmitt B. (2003). Customer experience management: A revolutionary approach to connecting with your customers. John Wiley \& sons 2003.Edition 1. ISBN 0471237744, 9780471237747.Pages 256

[27] Wong, A. and Sohal, A. (2003.Service quality and customer loyalty perspectives on two levels of retail relationships. Journal, Vol. 17 No. 5, pp. 495-513. https://doi.org/10.1108/08876040310486285

[28] Harris R.; Harris K.\& Baron, S. (2003): Theatrical service experiences: Dramatic script development with employees. International Journal of Service Industry Management 14(2): 184-199.

[29] Haeckel, S.H. \& Carbone, Lewis \& Berry, Leonard. (2003). How to Lead the Customer Experience. Marketing Management. 12. 18-23.

[30] Wytter Gordon (2003).How do you Measure THE Customer experience. Research Methods. Spring 2003.Pages6-7.

[31] Day, G. S., \& Hubbard, K. J. (2003).Customer Relationships Go Digital. Business strategy review. Volume 14, issue 1.PP 17-26.DOI 10.1111/1467-8616.00240. http://dx.doi.org/10.1111/1467-8616.00240.

[32] Stolterman, Erik \& Fors, Anna. (2004). Information Technology and the Good Life. International Federation for Information Processing Digital Library; Information Systems Research; 143. 10.1007/1-4020-8095-6_45.

[33] DeMark, Eugene F., and Robert R. Harcourt (2004).Companies Must Adapt to the Internet to Survive. The CPA journal. Vol. 74, No. 4. retieved from https://www.questia.com/magazine/1P3-623915201/companies-must-adapt-to-the-internet-tosurvive 
[34] Poulsson and Kale (2004). The Experience Economy and Commercial Experiences. The Marketing Review. Volume 4, Number 3, Autumn 2004, pp. 267-277(11), https://doi.org/10.1362/1469347042223445,

[35] Carbone Lewis P(2004). Clued In : How to keep customers coming back again and again. Pearson Publishing. May 2004.First edition. ISBN 9780131015500.

[36] Bond, A., Stone, M. How the automotive insurance claims experience affects customer retention. J Financ Serv Mark 9, 160-171 (2004). https://doi.org/10.1057/palgrave.fsm.4770149

[37] Thusy Alexandra ; Morris Langdon (2004):From CRM to Customer Experience: A New Realm for Innovation" Paris Business Digest Jan 2004.

[38] Hsieh, Yi-Ching \& Chiu, Hung-Chang \& Chiang, Mei-Yi. (2005). Maintaining a committed online customer: A study across search-experience-credence products. Journal of Retailing - J RETAIL. 81. 75-82. 10.1016/j.jretai.2005.01.006.

[39] Shaw, Colin (2005).Revolutionize Your Customer Experience. Palgrave Macmillan UK. 2005. Edition 1, Pages 220. ISBN 978-1-4039-3603-5.DOI 10.1057/9780230513457.

[40] Mithas, Sunil \& Krishnan, M. \& Fornell, Claes. (2005). Effect of Information Technology Investments on Customer Satisfaction: Theory and Evidence. SSRN Electronic Journal. $10.2139 /$ ssrn. 901643 . 